\title{
Sistema de Informação da Atenção Básica (SIAB): análise do uso de um sistema de informação em saúde na cidade de Parnamirim-RN
}

\author{
Valdete Honorato dos Santos \\ Graduada em Biblioteconomia pela Universidade Federal do Rio Grande do Norte (UFRN) \\ E-mail: valdetehonorato@gmail.com
}

\begin{abstract}
RESUMO:
Analisa o uso do Sistema de Informação da Atenção Básica (SIAB) como local de armazenamento constante de informações desenvolvidas pelas equipes de saúde na cidade de Parnamirim - RN. Aborda sobre a falta de conhecimento das equipes de saúdo acerca da utilização e acesso das informações do SIABI. Enfatiza que os sistemas de informação tem a função primordial de fornecer apoio informacional às atividades desenvolvidas pela instituição vinculada. Utiliza como metodologia a revisão de literatura, fazendo uso de suportes bibliográficos e digital. Realiza pesquisa de campo, e faz uso de questionário para a aquisição de informações. Expõe que os Sistemas informacionais de saúde evoluem rapidamente, conforme o avanço tecnológico, dos conceitos e métodos de armazenamento, tratamento e disseminação da informação. Avalia que um gestor deve preocupar-se com os dados gerados, ressaltando a importância de um profissional da informação, com competências em organizar, gerenciar e disseminar as informações do SIAB.
\end{abstract}

Palavras-chave: Sistema de Informação da Atenção Básica. Sistema de Informação em Saúde. Profissional da Informação.

\begin{abstract}
:
Analyzes the use of the Information System of Primary Care (SIAB) as a constant storage location information developed by health teams in the city of Parnamirim $\mathrm{RN}$. Discusses about the lack of knowledge of teams welcome on the use and access of Information System of Primary Care information. Emphasizes that information systems have the primary function of providing informational support to the activities developed by the institution linked. Use as methodology the literature review, using bibliographic and digital media. Conducts field research, and makes use of a questionnaire for the acquisition of information. States that health informational systems evolve rapidly as technological advances, concepts and methods of storage, processing and dissemination of information. Assesses that a manager must be concerned with the data generated, highlighting the importance of an information professional with skills in organizing, managing and disseminating information Information System of Primary Care.
\end{abstract}

Keywords: Information system of primary care. Health Information System. Information Professional. 


\section{INTRODUÇÃO}

A informação assume aspecto relevante dentro das organizações tendo em vista a contribuição significativa que a mesma pode oferecer aos gestores na tomada de decisão. Em relação a isso, pode-se compreender o valor da gestão da informação como meio facilitador desse processo em qualquer ambiente. Além disso, com o crescente fluxo de informações aumentando diariamente é imperativo apropriar-se de sistemas de informação que veicularão as informações de forma rápida e segura.

Desse modo, entende-se a necessidade da Secretaria Municipal de Saúde (SMS) da cidade de Parnamirim - RN em buscar manter um sistema de informação em saúde que possibilite o armazenamento adequado de informações pertinentes a suas ações. E é por meio do Sistema de Informação da Atenção Básica (SIAB) que se obtêm informações sobre cadastros de famílias, condições de moradia e saneamento, situação de saúde, produção e composição das equipes de saúde.

Verifica-se, no entanto, que as equipes de saúde do município desconhecem como acessar e utilizar esse sistema de informação. Por este motivo, pretende-se, nesta pesquisa, compreender como se dá o funcionamento do SIAB em relação às informações coletadas pelos Agentes Comunitários de Saúde (ACS); ou como as equipes de saúde podem acessar e utilizar as informações inseridas no SIAB; e ainda, quais são os fatores que determinam a interferência das informações coletadas e/ou fornecidas pelos ACS e equipes de saúde.

Diante das questões citadas, constatou-se a necessidade de buscar analisar a usabilidade do SIAB frente à demanda de informações fornecidas pelas equipes de saúde, tendo-se em conta a função deste tipo de sistema; averiguar a atuação do SIAB como fonte informacional; analisar a usabilidade do SIAB na tomada de decisão e, por fim, identificar a atuação do Bibliotecário nesse ambiente.

Isso faz crer que basicamente a criação e manutenção de sistemas de informação em saúde têm sido desenvolvidas principalmente para armazenar informações que possibilitem delinear estratégias de prevenção e de controle de epidemias. E o Sistema de Informação da Atenção Básica (SIAB) não é diferente da maioria, pois se caracteriza por ser um banco de dados que tem como objetivo agregar, armazenar e processar todas as informações relacionadas à Estratégia de Saúde da Família (ESF). Porém com um diferencial, pois são através dos dados 
informados ao SIAB que o Ministério da Saúde (MS) tem a possibilidade de creditar e repassar os incentivos financeiros aos municípios, contudo esse sistema não deve ser entendido e utilizado apenas com esta finalidade.

Uma vez que os sistemas de informação em saúde estão evoluindo de forma muito rápida, tendo em vista as mudanças tecnológicas, os conceitos e métodos para armazenar, tratar e disseminar as informações torna-se pertinente afirmar que esse sistema pode e deve ser utilizado da melhor forma por diferentes públicos, tais como os gestores e outros profissionais da saúde, acadêmicos e pesquisadores afins. Desse modo, torna-se imprescindível que todos os profissionais das equipes de saúde da família conheçam e utilizem os dados inseridos no SIAB com o objetivo de traçar estratégias, definir metas e identificar intervenções, assim como avaliar o resultado do trabalho desenvolvido.

A partir desses parâmetros entende-se que um sistema de informação em saúde precisa de um gestor que se preocupe com o produto direto, ou seja, os dados gerados, buscando utilizar a tecnologia da informação para desenvolver suas atividades. Nesse contexto, percebe-se a importância da atuação de um profissional capacitado para organizar, gerenciar e disseminar as informações do SIAB.

E é o Bibliotecário, como profissional da informação, que possui conhecimento e competência para desenvolver esse tipo de atividade em qualquer ambiente que necessite de informações organizadas para a sua recuperação rápida e eficaz. O sistema de informação em saúde atua enquanto instrumento flexível e dinâmico que oferece suporte e fortalece o processo de gerenciamento justamente no que diz respeito ao uso de informações para planejar, acompanhar e avaliar as atividades inerentes aos órgãos de saúde.

Para tratar deste tema, o presente capítulo está estruturado em oito partes, a saber: na segunda seção que segue o da introdução é feita uma abordagem relacionada à conceitualização dos sistemas de informação, apontando definições de autores especializados no assunto. Também é apresentado como estes sistemas atuam de forma geral, enfocando a evolução generalizada que ocorreu nos referidos sistemas.

Em seguida, na terceira seção, são introduzidos conceitos relacionados aos sistemas de informação em saúde e a sua implicação e envolvimento com os ditames da ciência da informação. Esta, por ser uma ciência interdisciplinar, 
demonstra a acentuada relevância da informação para a tomada de decisão em ambiente específico, neste caso, o da saúde.

$\mathrm{Na}$ quarta parte do texto é feito um aprofundamento das necessidades de uma adequada gestão da informação, visto que o principal propósito de um sistema de informação é oferecer apoio informacional às atividades desenvolvidas em determinada instituição possibilitando subsídios viáveis para a tomada de decisão. São citadas ainda, algumas atividades básicas que geram as demandas para o gerenciamento da informação, pois a informação desempenha uma ação diferenciada no que diz respeito aos produtos e serviços desenvolvidos, sendo de real valor o gerenciamento adequado.

$\mathrm{Na}$ quinta parte é feita uma abordagem sobre o profissional bibliotecário e sobre as suas competências e habilidades específicas para atuar nos variados mercados promissores e em expansão relacionados à informação, pois se percebe que o campo de atuação do bibliotecário é consideravelmente extenso, tendo em vista o fato de esse profissional ter como objeto de trabalho a informação.

Na sexta parte são apresentados os procedimentos metodológicos utilizados para o desenvolvimento da pesquisa.

A sétima parte é dedicada à exposição dos resultados obtidos, tendo em conta o contexto em que os dados foram coletados. Por fim, na oitava parte, os resultados são discutidos e as considerações finais da pesquisa são apresentadas.

\section{SISTEMAS DE INFORMAÇÃO}

De acordo com Audy, Andrade e Cidral (2005), os sistemas de informação atuam enquanto responsáveis pela disponibilização de informações necessárias para a tomada de decisão nos diversos níveis organizacionais de uma empresa, seja operacional, tático ou estratégico. Tendo-se em conta que a informação, deve ser entendida como insumo básico para o processo decisório que ocorre em cada um desses níveis. Nesse sentido, percebe-se que a informação necessária pode ser considerada como fator primordial para que as organizações possam realizar a integração e a administração dos processos de negócio e das funções empresariais, assim como possibilitar a tomada de decisão nos diversos níveis organizacionais favorecendo a obtenção de vantagens competitivas. 


\title{
2.1 CONCEITO
}

Os sistemas de informação são compreendidos com propósitos específicos para uma organização, no qual o principal objetivo é o de adquirir conhecimento que fundamente a gestão de seus serviços. Desse modo:

\begin{abstract}
Os sistemas de informação essencialmente transformam a informação em uma forma utilizável para a coordenação de fluxo de trabalho de uma empresa, ajudando empregados ou gerentes a tomar decisões, analisar e visualizar assuntos complexos e resolver outros tipos de problemas. Os sistemas de informação fazem isso através de um ciclo de três atividades básicas: entrada, processamento e saída. (LAUDON; LAUDON, 1999, p.4).
\end{abstract}

Nesse sentido percebe-se que o objetivo essencial de um sistema de informação é oferecer apoio informacional às atividades desenvolvidas pelos indivíduos nas instituições as quais estão vinculados. Desta forma, promovem desde o acesso rápido, integridade, veracidade e segurança das informações disponíveis até a garantia de obter informação essencialmente qualificada para uma boa tomada de decisão.

Sendo assim, é possível entender a teoria de Laudon e Laudon (1999) de que um sistema de informação funciona enquanto um conjunto de componentes capazes de trabalhar de forma unificada no sentido de coletar, recuperar, processar, armazenar e distribuir informação em empresas e organizações, visto que possibilita com facilidade o planejamento e controle, assim como a coordenação, a análise e o processo decisório. As vantagens em se utilizar banco de dados para organizar informações são inúmeras, dentre elas pode-se destacar a redução de redundância e da incoerência, a eliminação do conflito e a consolidação do gerenciamento dos dados, além da facilidade de acesso e uso das informações disponibilizadas.

Em contrapartida, O'brien (2004, p.06) considera os sistemas de informação como "um conjunto organizado de pessoas, hardware, software, redes de comunicação e recursos de dados que coleta, transforma e dissemina informações em uma organização." Dessa forma pode-se afirmar que os sistemas de informação facilitam o desenvolvimento das atividades dentro das organizações, pois promovem o processo de recuperação da informação de forma rápida e segura.

Dentro dessa perspectiva O'brien (2004, p. 11) elenca os componentes que atuam em qualquer tipo de sistema de informação: 
- Recursos Humanos: Que pode ser formado pelos especialistas e usuários finais (Analistas de Sistemas, Programadores, Operadores de Computador e Bibliotecários).

- Recursos de Hardware: Este que é formado pelas máquinas (computadores, monitores de vídeo, unidades de disco magnético, impressoras, scanners óticos). Além das mídias: disquetes, fita magnética, cartões de plásticos e formulários em papel.

- Recursos de Software: O qual é constituído pelos programas (programas de sistemas operacionais, programas de planilhas eletrônicas e programas de processamento de textos), além dos procedimentos (procedimentos de entrada de dados, procedimentos de correção de erros, procedimentos de distribuição de informação).

- Recursos de dados: Que consiste na descrição de produtos, cadastro de usuários, arquivos de funcionários e banco de dados de estoque.

- Recursos de Rede: são os meios de comunicação, processadores de comunicação, acesso a redes e software de controle.

- Produtos de Informação: são os relatórios administrativos e documentos empresariais utilizando texto e demonstrativos gráficos, respostas em áudio e formulários em papel.

Assim, os componentes apresentados facilitam o gerenciamento dos sistemas de informação tendo em vista que é necessária a sincronia entre todos os elementos para que a informação flua de forma satisfatória e auxilie na tomada de decisão dentro das instituições.

Nesse sentido, Audy, Andrade e Cidral (2005) dizem que o principal objetivo dos Sistemas de Informação é disponibilizar para a organização as informações imprescindíveis para que ela atue em um determinado ambiente. O sistema de informação é gerado a partir de um ciclo contínuo de informações disponibilizadas, na qual as organizações podem analisar problemas e oportunidades para criar e desenvolver novos produtos, serviços e formas de operação que propiciem a obtenção de vantagens competitivas. Sendo assim, pode-se perceber, de maneira geral, através do gráfico abaixo como acontece o fluxo das atividades em um sistema de informação. 
GRÁFICO 1: Ciclo de atividades em Sistemas de Informação

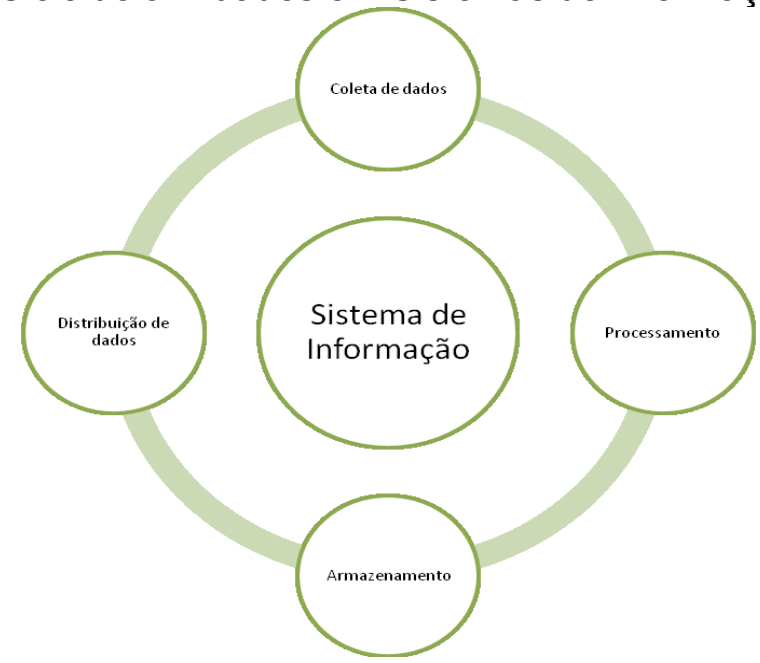

Fonte: Elaborado pela autora com base em Audy, Andrade e Cidral (2005).

A partir desta imagem, entende-se que para o correto funcionamento de um sistema de informação é necessário que ocorra um ciclo de atividades inerentes a instituição, onde inicialmente será feita uma coleta de dados específica, estes dados serão manipulados e transformados em informação. Em última instância, eles serão processados e armazenados, para enfim serem distribuídos, pois o contínuo fluxo de dados no sistema proporciona todas as informações necessárias para a sobrevivência da organização.

Desse modo, segundo O'brien (2004), a principal função de um sistema de informação representa, dentre outras, uma contribuição relevante e imprescindível para a eficiência operacional e produtividade da instituição, atuando também como importante fonte de informação e apoio eficaz na promoção da tomada de decisão pelos gerentes e profissionais da empresa, pois os sistemas de informação se estabelecem como uma necessidade vital para o desenvolvimento de produtos e serviços competitivos que oferecerão à organização uma vantagem estratégica no mercado global.

Sendo assim, é pertinente dizer que um sistema de informação atua enquanto uma combinação de ações relacionadas ao uso de plataformas de tecnologia informacional, ao ciclo de informação e a um grupo de pessoas para que de forma organizada possa chegar ao alcance dos objetivos de determinada instituição. Desse modo cabe buscar entender, de maneira geral, como se deu a evolução dos sistemas de informação. 


\subsection{EVOLUÇÃO}

É através de sistemas que toda atividade humana é organizada, por isso, entende-se que as atividades organizacionais também interatuam e adaptam os sistemas, visando atingirem objetivos comuns com base em informações organizadas. Assim, os sistemas de informação podem ser compreendidos como um sistema no qual a informação surge como principal elemento.

Segundo Medeiros (2002) a abordagem sobre sistemas de informação é um assunto que vem sendo tratado desde a época dos filósofos pré-socráticos, de Platão, Aristóteles, até os dias atuais, porém com acentuadas diferenças entre as formas de tratamento do tema. Sabe-se que nos primeiros tempos, as ciências eram observadas como ramificações da filosofia. Desse modo, a abordagem sobre sistemas confundia-se com a filosofia na medida em que esta se preocupava com os problemas globais.

Assim, enquanto as ciências evoluíam, o conhecimento humano era aprofundado e uma única pessoa já não conseguia dominar todas as nuances e descobertas de cada ramo da filosofia. Diante disso, no intuito de compreender para melhor solucionar os problemas que surgiam, buscava-se classificar os assuntos sob distintos aspectos que podiam ser de cunho educacional, social, econômico ou científico-tecnológico, entre outros.

Sendo assim, percebe-se que o uso de equipes interdisciplinares é um traço marcante da abordagem de sistemas, pois tem como objetivo o estabelecimento de uma linguagem comum entre as diferentes áreas que constituem o repertório cognitivo do ser humano, dando ênfase à importância do intercâmbio e avaliação da informação, tanto quanto a sua difusão. Desse modo, a partir da Revolução Industrial em meados do século $X X$, o fluxo de informação existente nas instituições dobrou devido ao crescimento das atividades técnicas e científicas e isso se intensificou através do uso contínuo de tecnologias de reprodução de documentos, enfatizado pelo processo de globalização.

A partir disso, foi gerado um aumento significativo de informações registradas provocando reflexão acerca da distinção entre a definição de dados e informação, como também surgiu a necessidade imprescindível em agregar informações sob uma visão sistemática, a fim de facilitar o seu acesso. Por isso, de acordo com Targino (2006, p.219): 
Graças à força crescente da informação como fator de transmutações sociais e à concepção do sistema como princípio organizador do conhecimento, o significado da informação nos sistemas adota função estratégica. Isto significa que a informação nas organizações concilia metas e objetivos com formatos e conteúdos diversificados das diversificadas fontes de informação, estruturadas ou não, em sistemas disponibilizados no ambiente organizacional.

Com base nesta perspectiva, entende-se que um sistema quando bem estruturado e organizado pode ser capaz de oferecer recursos para entender, interpretar e adicionar valor à informação tornando-a mais significativa. A seguir será introduzida uma abordagem detalhada do foco principal da pesquisa, neste caso, um Sistema de Informação em Saúde (SIS).

\section{SISTEMAS DE INFORMAÇÃO EM SAÚDE}

A informação pode ser considerada como fator primordial na produção de conhecimento atuando como elemento de sobrevivência de qualquer profissional, assim como quando alocada nos sistemas de informação em saúde traduz-se como garantia de melhor qualidade de vida para a população, já que o desenvolvimento e manutenção dos sistemas têm sido norteados para a prevenção e o controle de epidemias e surtos.

Nesse sentido, é possível identificar a atuação relevante dos sistemas de informação em saúde, já que estes podem viabilizar o gerenciamento das informações de forma rápida e segura.

O objetivo final de um produto de informação ou de um sistema de informação deve ser pensado em termos dos usos dados à informação e dos efeitos resultantes desses usos nas atividades dos usuários. A função mais importante do produto ou do sistema é, portanto, a forma como a informação modifica a realização dessas atividades. (LE COADIC, 2004, p.38).

Desse modo entende-se que os sistemas de informação devem ser orientados e projetados para possibilitar o uso facilitado entre os usuários. Entendese que "pessoas ainda são os melhores 'meios' para identificar, categorizar, filtrar, interpretar e integrar a informação." (DAVENPORT, 2002, p.53). Isso permite afirmar que a utilidade da informação depende consideravelmente de como são armazenadas, organizadas e acessadas. Porém, para a Organização PanAmericana da Saúde (OPAS), os sistemas de informação em saúde são: 
Combinações de dados estatísticos vitais e de saúde procedentes de múltiplas origens, utilizados na produção de informações sobre as necessidades de saúde, recursos, custos e utilização dos serviços de saúde, bem como resultados da utilização destes serviços pela população de uma determinada área administrativa. O termo pode ser usado, também, para descrever a saída automática da informação armazenada em computadores como resposta a estímulos programados. (OPAS, 2002, p.52).

Assim é possível dizer que as funções de um sistema de informação dependem da estrutura disponível, visto que as organizações em saúde apresentam complexidades que envolvem diversos fatores.

\subsection{SISTEMA DE INFORMAÇÃO DA ATENÇÃO BÁSICA (SIAB)}

De acordo com o Ministério da Saúde (BRASIL, 2008) , o Sistema de Informação da Atenção Básica (SIAB) teve sua implantação registrada no ano de 1998, em substituição ao Sistema de Informação do Programa de Agentes Comunitários de Saúde (SIPACS), para o acompanhamento das ações e dos resultados das atividades realizadas pelas equipes do Programa Saúde da Família (PSF). Esse sistema foi desenvolvido para conter pequenos dados informacionais, objetivando diagnóstico de saúde da comunidade, das intervenções realizadas, e os resultados sócio-sanitários alcançados pelas equipes de saúde. Para tanto "os sistemas de informações têm, basicamente, o objetivo de aquisição do conhecimento que deve fundamentar a gestão dos serviços." (BRASIL, 2009, p.09).

Nesse sentido, o SIAB foi desenvolvido como um instrumento gerencial dos sistemas locais de saúde e incorporou em sua formulação dados conceituais como território, problema e responsabilidade sanitária, já que estes são conceitos inseridos no contexto de reorganização do Sistema Único de Saúde (SUS) no país, o que fez com que assumisse características distintas dos demais sistemas existentes. Desse modo:

No contexto, marcado pela valorização da gestão participativa, municípios e estados alçaram o estatuto de novos e importantes atores, uma vez que passaram a ter papel fundamental, inclusive na geração e no uso de dados necessários aos diferentes subsistemas de informação em saúde existentes no país. (BRASIL, 2009, p.8).

\footnotetext{
${ }^{1}$ Documento eletrônico não paginado.
} 
Sendo assim, tais características significaram avanços concretos no campo da informação em saúde, pois por meio do SIAB é que se obtêm informações sobre cadastros de famílias, condições de moradia e saneamento, situação de saúde, produção e composição das equipes de saúde. A reunião destes dados possibilita a micro-espacialização de problemas de saúde e de avaliação de intervenções, assim como a utilização mais rápida e oportuna da informação, a produção de indicadores capazes de cobrir todo o ciclo de organização das ações de saúde a partir da identificação de problemas, bem como a consolidação progressiva da informação, partindo de níveis menos agregados para os mais agregados. (BRASIL, 2008)2.

Diante dessa perspectiva, torna-se evidente que o SIAB, como banco de dados, possui a finalidade de agregar, armazenar e processar toda a informação relacionada às ações de saúde no PACS/PSF, atualmente denominada Estratégia Saúde da Família (ESF). De acordo com Silva e Laprega (2005, p.1822) "o SIAB representa, então, potencialmente, uma fonte de dados de grande valor para a realização do diagnóstico de saúde de determinada área de abrangência, norteando o planejamento e avaliação de ações em saúde."

Compreende-se, portanto, que o SIAB é uma rica fonte de dados, pois abrange um grande número de importantes informações de saúde coletadas em âmbito local, visto que "a informação tem sua origem na coleta de dados, os quais por sua vez, são organizados e recebem significado de acordo com um contexto delimitado" (BEUREN, 1998, p.44), além de servir para que as equipes de saúde da família desenvolvam suas estratégias de atuação e, também, como fonte para vários tipos de pesquisa.

Segundo o Ministério da Saúde (BRASIL, 2003, p.5) "o SIAB amplia o leque de informações, com novos instrumentos de coleta e de consolidação que permitirão sua utilização por toda a equipe de saúde da unidade básica." Para isso, esse sistema é composto por um programa de computador, o software SIAB e por algumas fichas como instrumento de coleta e consolidação dos dados obtidos pela ESF. Convém ressaltar que o adequado preenchimento desses instrumentos cumpre o fluxo de dados até as fases de processamento, consolidação, análise e difusão e, apenas após essa fase, contribuem para as funções de gestão relacionada ao cuidado do paciente, bem como para a gestão do sistema como um todo.

\footnotetext{
2 Documento eletrônico não paginado.
} 
A seguir é possível a compreensão da atuação desses instrumentos no sistema de informação.

\subsubsection{Instrumentos de coleta e consolidação dos dados}

Por ser um sistema planejado para agregar e para processar as informações coletadas e armazenadas sobre a população visitada pela ESF, infere-se que quanto maior a reciprocidade entre a informação fornecida ao sistema e as necessidades informativas das equipes que dela necessitam, melhores poderão ser as ações desenvolvidas com base neste. Nesse sentido, de acordo com a Organização PanAmericana da Saúde (2002, p.17):

\footnotetext{
Os instrumentos de coleta de dados devem ser projetados de acordo com as finalidades e objetivos visados pelo sistema de informação, nos quais devem estar incluídas, fundamentalmente, aquelas variáveis que serão utilizadas segundo um plano de análise preestabelecido.
}

Desse modo, entende-se que os instrumentos de coleta de dados devem conter informações referentes aos principais fatores de risco, para que com base nesses fatores seja possível o estabelecimento de prioridades e a orientação acerca das medidas de intervenção de saúde. Nesse sentido, de acordo com o Ministério da Saúde (BRASIL, 2003) e Bittar et al. (2009) os principais instrumentos usados pelo PACS/ PSF para a coleta de dados armazenados no SIAB são:

- ficha $A$, que contém informações sobre o cadastro das famílias e levantamento dos dados sócio-sanitários do município. São fichas preenchidas pelos ACS no momento do cadastramento das famílias;

- as fichas de acompanhamento de grupos de risco e de problemas prioritários de saúde, como no caso dos Hipertensos (ficha B-HA), diabéticos (ficha B-DIA), gestantes (ficha B-GES) e crianças (ficha $C)^{3}$ com idade inferior a 5 anos, também os casos de tuberculose (ficha BTB)e hanseníase (ficha B-HAN), estas são preenchidas mensalmente pelo ACS no momento de realização das visitas domiciliares;

\footnotetext{
${ }^{3}$ Cópia/espelho do cartão de vacina.
} 
- as fichas de registro de atividades, procedimentos e notificações produzidas mensalmente por todos os profissionais das equipes de saúde (ficha D);

- os relatórios de situação de saúde e acompanhamento das famílias (SSA2), consolidando informações das fichas $A, B, C$ e $D$ referentes às microáreas de uma mesma área;

- E por fim, os relatórios de produção e marcadores ${ }^{4}$ para avaliação (PMA2), no qual consolida mensalmente a produção de serviços e a ocorrência de doenças e/ou de situações consideradas como marcadoras por área.

Isso permite afirmar que os dados gerados por meio das fichas e relatórios de indicadores do SIAB atribuem agilidade ao sistema gerando informação adequada no processo de decisão em saúde favorecendo sua utilização como instrumento de planejamento e gestão da informação em âmbito local.

\section{GESTÃO DA INFORMAÇÃO PARA TOMADA DE DECISÃO}

A quantidade crescente de informações produzidas requer das organizações políticas informacionais que propiciem a gestão, o processo e a disseminação da informação de forma eficaz, já que a informação de qualidade tem um valor significativo dentro das organizações, como destaca Beuren (1998, p.43):

A informação é fundamental no apoio as estratégias e processos de tomada
de decisão, bem como no controle das operações empresarias. Sua
utilização representa uma intervenção no processo de gestão, podendo,
inclusive, provocar mudança organizacional, à medida que afeta os diversos
elementos que compõem o sistema de gestão. Esse recurso vital da
organização, quando devidamente estruturado, integra as funções das
varias unidades da empresa, por meio dos diversos sistemas
organizacionais.

Portanto para que tais informações alcancem o seu objetivo é necessário que sejam tratadas por meio de padrões e procedimentos que viabilizem sua disponibilização de forma organizada e segura. Nesse sentido, quando a organização reconhece o papel positivo que a informação representa, cabe ao gestor refletir sobre a eficácia da gestão da informação. Torna-se evidente que para manter

\footnotetext{
4 "Eventos mórbidos ou situações indesejáveis que devem ser notificados com o objetivo de, a médio prazo, avaliar as mudanças no quadro de saúde da população adscrita."(BRASIL, 2003, p.55).
} 
esse processo de gestão, as informações precisam apresentar-se de forma que seja definida e utilizada como uma tática gerencial oferecendo possibilidades de escolhas e de ênfases sobre qual tipo de negócios os gestores precisam se dedicar, que produtos criar, e quais mercados atingir para alcançar os objetivos (DAVENPORT, 2002).

Dessa forma, a informação funciona como uma base essencial para a adoção de estratégias e procedimentos de tomada de decisão, bem como no domínio das operações organizacionais. Segundo Silva e Tomaél (2007) 5 "a gestão da informação é responsável por gerir tanto os recursos internos quanto os externos à organização". Assim, a Gestão da Informação pode ser entendida como processo que consiste nas atividades de busca, identificação, classificação, processamento, armazenamento e disseminação de informações, independentemente do formato ou meio em que se encontra, com a finalidade de levar a informação certa para o indivíduo certo.

De acordo com Beuren (1998, p. 15) "a informação gerada nas empresas deve assumir o caráter de dar o suporte informativo adequado, para que os gestores percebam a eficiência e a eficácia empresarial como uma necessidade contínua e sustentada." Nesse contexto, o gerenciamento da informação de forma eficaz ocasiona resultados positivos para a instituição, quando identificada as necessidades de informação da organização. Desta forma, a sua gestão torna-se imprescindível para que os sistemas de informação viabilizem o seu fluxo de forma rápida e segura. Para tanto:

\begin{abstract}
O principal objetivo da gestão da informação é identificar e potencializar os recursos informacionais de uma organização e sua capacidade de informação, ensiná-la a aprender e adaptar-se às mudanças ambientais. A criação da informação, aquisição, armazenamento, análise e uso provêem a estrutura para o suporte ao crescimento e ao desenvolvimento de uma organização inteligente, adaptada às exigências e às novidades da ambiência em que se encontra. (TARAPANOFF, 2001, p.44).
\end{abstract}

Sendo assim, gerenciar sistemas de informação em saúde é uma maneira de auxiliar o administrador da instituição no processo decisório, já que o sistema é desenvolvido com base no conhecimento específico do negócio, com uma metodologia apropriada para selecionar as informações estratégicas e identificar as atividades críticas do empreendimento. Nesse sentido, sistema de informação é

\footnotetext{
${ }^{5}$ Documento eletrônico não paginado.
} 
entendido como uma eficiente ferramenta utilizada para manipular os dados gerados dentro da organização através do uso de computadores. Batista (2004, p.36) afirma que:

O conjunto de informações que possuem ação direta sobre a organização está disponível no mercado, mas a manipulação diária dessas informações necessita da ajuda de computadores para que se possa ter uma boa visão desse universo, utilizando conectividade, processamento de informações e transferência eletrônica de dados.

Desse modo, percebe-se que o gestor de um sistema de informação em saúde necessita se preocupar com o produto direto, ou seja, com os dados gerados, assim como buscar utilizar a tecnologia da informação para desenvolver suas atividades. Ele não deve perder de vista que o sistema de informação em saúde atua enquanto instrumento flexível e dinâmico oferecendo suporte e fortalecendo o processo de gerenciamento no que diz respeito ao uso de informações para planejar, acompanhar e avaliar as atividades inerentes aos órgãos de saúde.

Em relação a este fato, Batista (2004, p.39) diz que "Os processos gerenciais são traduzidos para os sistemas de informação para melhorar seja o controle interno da empresa, seja o seu tempo de resposta a todas as flutuações de mercado, permitindo uma tomada de decisões mais eficaz." Desse modo, entende-se que qualquer profissional que precisa manipular informações para desenvolver estratégias de ação ou tomada de decisão precisa conhecer as diferenças entre as informações existentes na organização e saber como definir corretamente uma informação necessária. Sabe-se que uma informação pode ser ao mesmo tempo a base para a tomada de decisões e o resultado direto de uma ação.

De acordo com Le Coadic (2004, p.38) "usar a informação é trabalhar com a matéria informação para obter um efeito que satisfaça a uma necessidade de informação." É claro que a utilização de sistemas de informações enquanto instrumento de definição do perfil epidemiológico ${ }^{6}$, ações de planejamento e avaliação de serviço, requerem uma avaliação da qualidade dos dados e informações geradas. Tal avaliação vem garantir, desse modo, a confiabilidade no momento de sua utilização nos processos de decisão, também é preciso que haja um gerenciamento do sistema fazendo uso de diretrizes de gestão para que seja possível uma triagem desta informação afim de que seja disponibilizada.

\footnotetext{
${ }^{6}$ Estudo da frequência, da distribuição e dos determinantes dos estados ou eventos relacionados à saúde.
} 
Nesse contexto, os sistemas de informação em saúde tornam-se viáveis ao serem adaptados para tratamento em âmbito local, possibilitando a sua utilização enquanto instrumento de reorganização e definição das ações de saúde. Nesse sentido, a informação somente adquire determinada relevância a partir de seu papel na tomada de decisão. Cabe, portanto, apresentar quais são as atividades básicas que geram as demandas para o gerenciamento da informação, identificadas por Davenport (2002) como um processo genérico que acontece em quatro passos como mostra a figura abaixo:

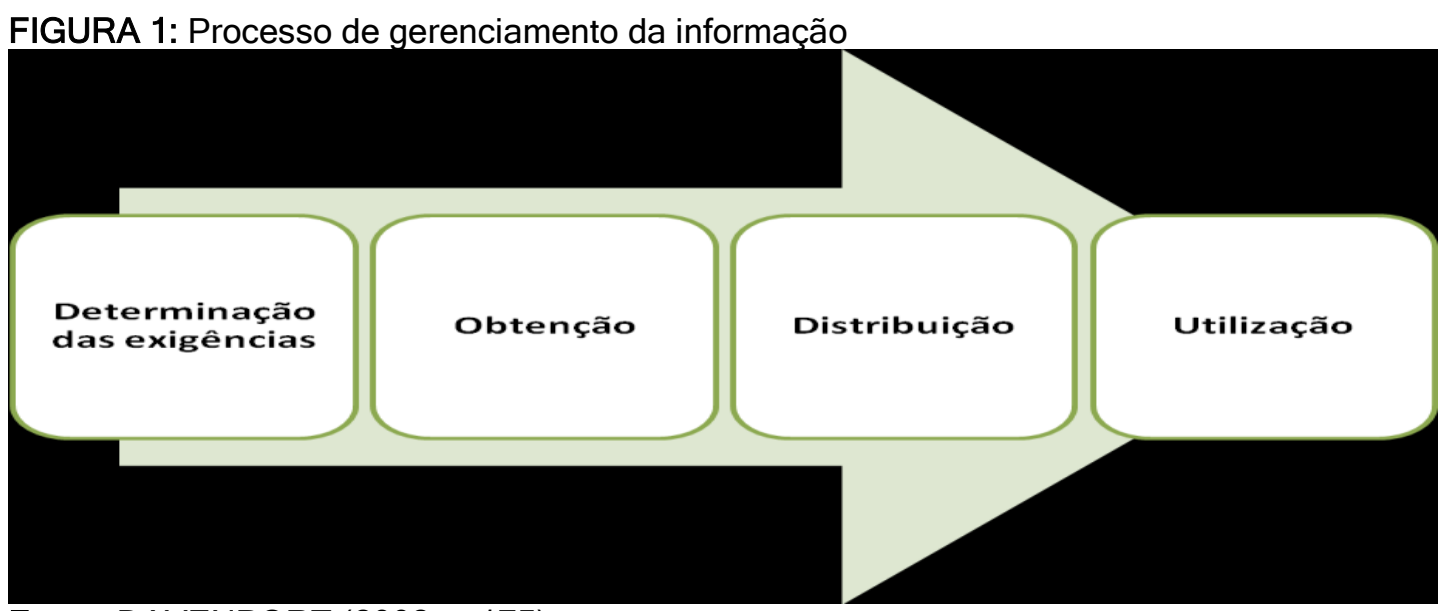

Fonte: DAVENPORT (2002, p.175).

Determinação das exigências da informação - envolve identificar como os gerentes e os funcionários percebem seus ambientes informacionais. Sob várias perspectivas, tais como, política, psicológica, cultural e estratégica, assim como também buscar fazer uso de avaliações correspondentes, não apenas individual como também organizacional. Precisam conseguir definir o problema e a situação em que está inserido, tornando a informação significativa, pois para que um modelo de processo de gerenciamento informacional seja significativo precisa refletir sobre a turbulência, a volatilidade e a complexidade dos mercados, dos locais de trabalho e da mente humana.

Obtenção de informações - incorpora um sistema de aquisição contínua, na qual estão incorporadas várias atividades, tais como, exploração do ambiente informacional (que depende de uma combinação de abordagens: a automatizada e a humana); classificação da informação em uma estrutura pertinente (define esquemas iniciais, monitora o método de coleta para verificar quais novas categorias são necessárias, atualizam o esquema a intervalos regulares); formatação e estruturação das informações (os documentos são as maneiras mais óbvias e úteis de estruturar a 
informação, visto que possui estrutura, contexto e excluem uma quantidade suficiente de informações para que o restante possa ser selecionado e resumido).

Distribuição - envolve a ligação de gerentes e funcionários com a informação de que necessitam. Pois se os passos anteriores estiverem funcionando corretamente, então a distribuição da informação acontecerá de maneira efetiva, já que será definida a consciência de que a informação possui valor para a organização, sendo que a disponibilização em formato apropriado torna mais fácil a distribuição. Assim, para preencher a necessidade de informação e obtê-la de forma correta, os usuários devem ser estimulados a procurá-la, sem tornarem-se receptores passivos dos dados que outras pessoas considerem importantes. Visto que, uma vez armazenados, os dados podem se movimentar pelas redes com considerável agilidade, e as máquinas distribuem corretamente certos tipos de dados, incluindo os altamente estruturados, os atualizados com frequência, os que precisam ser enviados a múltiplas localizações de uma única vez e a locais geograficamente distantes e os que precisam ficar armazenados para ser acessado pelos usuários.

Uso da informação - considerada a etapa final do processo de gerenciamento da informação, neste quarto e último passo é onde serão avaliados os níveis de aceitação e uso das informações disponíveis, através de determinados métodos, tais como, estimativas (com a informação eletrônica é possível estimar os acessos a um banco de dados ou a um depósito de documentos), ações simbólicas (podem ser usados com eficácia para estimular o uso maior da informação e a troca de conhecimento), contextos institucionais (reuniões regulares entre gerentes fornecem o contexto mais comum para o uso da informação, através da apresentação de balancetes, relatórios sistemáticos, etc.) e as avaliações de desempenho (por meio de recompensas e punições pessoais, ou seja, identificando se as informações estão sendo utilizadas para basear a atividades internas, com a possibilidade de ser estimada e melhorada através de outros processos).

Assim, fica evidente o entendimento de que a adoção desses processos aliados à tecnologia da informação contribui de forma significativa no aperfeiçoamento e consolidação de uma gestão de sistemas de informação, visto que auxilia na orientação das ações de saúde segundo as necessidades e demandas locais tendo por base o valor que a informação possui quando estruturada, organizada e utilizada de maneira correta. 
Sendo assim, é notável a relevância da atuação do Bibliotecário neste processo, como o profissional que possui conhecimento e competência para desenvolver atividades relacionadas à organização, disponibilização e recuperação rápida e eficaz da informação em qualquer ambiente. Na próxima sessão, será abordada de forma mais detalhada como atua este profissional em ambientes que necessitam de informação organizada e acessível.

\section{ATUAÇÃO DO BIBLIOTECÁRIO}

De acordo com Valentim (2002), a formação do profissional da informação está apoiada nas competências, habilidades, atitudes, procedimentos e novos paradigmas de acesso e uso da informação. Para que com base nessa formação, seja possível o desempenho de variadas atividades em diferentes áreas do conhecimento, pois o tripé informação, tecnologia da informação e telecomunicação modifica a sociedade, e como consequência transforma suas demandas. De acordo com Santos (2002, p.103):

\footnotetext{
A informação é a peça fundamental no desenvolvimento das atividades do profissional da biblioteconomia. O conhecimento de seu fluxo, a percepção do ambiente informacional, a destreza no manuseio e no uso de recursos tecnológicos que favoreçam o acesso, o tratamento, a recuperação e o uso de informações facilita a geração de novos conhecimentos.
}

Desse modo, a partir do momento em que toda a informação que é registrada e armazenada pode ser socializada, torna-se objeto de trabalho do bibliotecário. Tal objeto de trabalho, neste caso, "faz parte do cotidiano de toda a humanidade, mas se diferencia daquela 'informação' do senso comum na medida em que o mesmo foi registrado e pode ser socializado." (SMIT; BARRETO, 2002, p.21).

Isso pressupõe que nem toda a informação é armazenada ou registrada, ao ponto de ter seu valor traduzido em termos de cultura, memória, ciência, apoio a decisão, informação necessária à pesquisa, dentre outras necessidades. No entanto, ela pode oferecer a possibilidade da criação de estoques mantidos quando lhe for atribuída uma utilidade, existir um banco de dados, uma bibliotecas, entre outros. Ao se estocar a informação, esta passa a ter uma existência institucional e, portanto social. 
Em razão disso, o bibliotecário, para poder criar mecanismos de atuação na sociedade, precisa compreender que realidade está vivenciando para enfrentar as mudanças que são cada vez maiores e, assim, antecipar as tendências e perspectivas futuras da sociedade. E dessa forma buscar a melhoria contínua na execução das atividades profissionais oferecendo resultados com mais qualidade.

\title{
5.1 PERFIL DO BIBLIOTECÁRIO
}

De acordo com Valentim (2000), o Bibliotecário pode e deve trabalhar a informação como um fator de competitividade organizacional, tanto em organização pública, quanto em organização privada, pois a informação quando adequadamente ordenada e estruturada poderá contribuir com inúmeros fatores que beneficiarão um gerenciamento de sucesso. Em razão disso, fica evidenciado que:

\begin{abstract}
A formação do profissional da informação incorpora, portanto, algumas técnicas e procedimentos da biblioteconomia, mas acrescenta aos mesmos os imperativos do trato da informação (muito mais mutantes e sujeitos a localismos que a organização de documentos de um acervo físico) e a compreensão tanto de sua origem (por que e como se produz, registra e divulga a informação) como de suas finalidades sociais (como se utiliza a informação para gerar o conhecimento). (SMIT; BARRETO, 2002, p.22).
\end{abstract}

Compreende-se, portanto, que são necessárias competências e habilidades inerentes ao profissional da informação para participar das várias fases do processo de geração e transferência da informação. Segundo Valentim (2000) a informação como objeto de trabalho contribui para a tomada de decisão, como fator de produção. Visto que quanto maior o nível tecnológico de um produto, mais aumenta a necessidade de informação nas etapas de concepção, ensaios e produção propriamente, como insumo na inovação tecnológica, e como fator de gestão contribuindo para multiplicar a sinergia entre os indivíduos da organização.

Nesse aspecto, Davenport (2002, p.182) ressalta que "os bibliotecários são os exploradores da informação, auxiliados pelo uso eficiente da tecnologia da informação". Entende-se que o perfil do bibliotecário deve ser o de um profissional que busca constante atualização, visto que de acordo com Santos (2000) o perfil desse profissional deve ser sempre o de conhecedor das inovadoras tecnologias disponíveis para que assim tenha condições de ampliar o universo de seu ambiente de trabalho colocando as redes e os recursos informacionais a disposição de seus usuários. 
Sendo assim, segundo Valentim (2002) foram definidas competências e habilidades ao profissional da informação no IV Encuentro de Directores de Escuelas de Bibliotecología y Ciencia de La Informácion del Mercosur, distribuídas em quatro categorias: Competências de Comunicação e Expressão, esta que engloba entre outras a competência para capacitar e orientar os usuários para um melhor uso dos recursos de informação disponíveis nas unidades de informação, assim como planejar e executar estudos de usuários e formação de usuários da informação; Competências Técnico-Científicas, relacionado ao ato de desenvolver as atividades técnicas da profissão, tais como, desenvolver e executar o processamento de documentos em distintos suportes em unidades, sistemas e serviços de informação, assim como, selecionar, registrar, armazenar, recuperar e difundir a informação gravada em qualquer meio para os usuários de unidades, serviços e sistemas de informação, entre outras; Competências Gerenciais e Competências Sociais e Políticas.

Já no Brasil, especialistas do Ministério da Educação e Cultura (MEC) definem as competências e habilidades necessárias para o profissional da informação. Dentre elas estão elencadas a capacidade para produzir e divulgar conhecimentos, a geração de produtos resultantes dos conhecimentos adquiridos, competência para gerenciar instituições, serviços e sistemas de documentação e informação entre outros. Sendo destacada também a adesão de novos paradigmas pelos profissionais da informação, tais como, ter a informação como objeto de trabalho e pesquisa; buscar praticar atualizadas formas de mediação da informação; saber trabalhar em equipes multidisciplinares; conhecer realmente as necessidades informacionais do indivíduo ou grupos que fazem parte da comunidade usuária de uma determinada unidade de informação, ter consciência da relevância do papel estratégico da informação etc.

Em suma, presume-se que o perfil do profissional bibliotecário flui satisfatoriamente de acordo com as competências e habilidades adquiridas ao longo de toda a vida acadêmica por meio dos conteúdos formadores e prossegue na atuação profissional quando incorpora perfil empreendedor e continua uma postura investigativa e crítica, gerando disposição de busca incessante que o torna sempre competente para atuar em favor da sociedade. 


\section{METODOLOGIA}

Para a efetivação do presente estudo de caso foram utilizadas algumas técnicas que mais se adequavam ao propósito desta pesquisa. Foram, portanto, levadas a cabo a pesquisa bibliográfica e à documentação direta, esta última constituída de levantamento de dados in loco, conhecida como pesquisa de campo. Segundo Marconi e Lakatos (1990, p. 75) este tipo de pesquisa."é aquela utilizada com o objetivo de conseguir informações e/ou conhecimentos acerca de um problema, para o qual se procura uma resposta, [...]."Entende-se, portanto que significa mais que uma simples coleta de dados, pois para uma pesquisa de campo satisfatória torna-se necessário que haja um adequado controle, assim como objetivos preestabelecidos que buscam orientar e discriminar o que deve ser coletado.

Assim, também por meio de pesquisa classificada como descritiva foi possivel desenvolver uma abordagem qualitativa dos problemas apresentados. De acordo com Gil (2010) e Matias-Pereira (2010) a pesquisa descritiva é aquela que possibilita descrever as características de determinada população e estabelecer relação entre variáveis, envolvendo o uso de técnicas padronizadas de coleta de dados. Neste caso foi adotado o uso de questionários e observação sistemática, caracterizando-se, assim, como uma forma de levantamento de dados.

Para o questionário, a forma das perguntas foi classificada tanto como perguntas fechadas ou dicotômicas, já que de acordo com Marconi e Lakatos (1990) oferecem alternativas fixas no qual o questionado escolhe sua resposta entre duas únicas opções, sim ou não. Houve também perguntas abertas para permitir a emissão de opinião por parte do informante usando linguagem própria.

Em relação à observação sistemática, Gil (2010) diz que é uma técnica adequada a estudos de casos descritivos, pois, a partir dessas observações, o pesquisador sabe quais os aspectos da comunidade, da organização ou do grupo possuem teor significativo para alcançar a finalidade desejada. Desse modo, a técnica oferece os subsídios necessários capazes de organizar e desenvolver um plano de observação para orientar a coleta, análise e interpretação dos dados.

Faz-se necessário retomar que o principal objetivo da pesquisa tem sido o de analisar o uso do SIAB pelas equipes de PACS/PSF frente à demanda de informações fornecidas pelos mesmos, identificando os fatores que possibilitam o 
acesso ao sistema de informação, principal elo de comunicação entre as Unidades Básicas de Saúde (UBS), Secretaria Municipal de Saúde (SMS) e Ministério da Saúde (MS).

Em razão disso, é pertinente expor que a motivação para explorar esse tema está relacionada às experiências pessoais com relação à inabilidade e falta de conhecimento de como acessar e utilizar as informações desse sistema especificamente.

Sob essa perspectiva a pesquisa foi desenvolvida em distintos locais da cidade, pois o município possui em torno de 42 equipes de PSF e 172 ACS distribuídas em 27 UBS e casas de apoio. Foram escolhidas para responder aos questionamentos propostos uma quantidade mínima de 10 equipes $^{7}$ de PSF e 20 $A C S$, visto que uma quantidade maior exigiria um longo período de tempo a mais do que o estabelecido pelo cronograma.

Desse modo, foram aplicados 40 questionários a todos os profissionais da saúde do PACS/PSF escolhidos aleatoriamente por meio de sorteio, obtendo-se um retorno de $77,5 \%$ dos questionários respondidos. Sendo que entre os $22,5 \%$ estão os profissionais que responderam ao questionário ou não o devolveram em tempo hábil.

A seguir, pode-se verificar a análise e contextualização dos dados obtidos na pesquisa.

\section{CONTEXTUALIZAÇÃO DOS DADOS COLETADOS}

Os resultados quantitativos da pesquisa estão dispostos em gráficos e tabelas para melhor visualização e contextualização dos dados coletados. Desse modo, visando obter uma identificação geral do público pesquisado, buscou-se saber, a princípio, o grau de instrução e o tempo de serviço de cada possível usuário do sistema em questão, conforme a tabela abaixo.

TABELA 1: Dados de Identificação do público pesquisado.

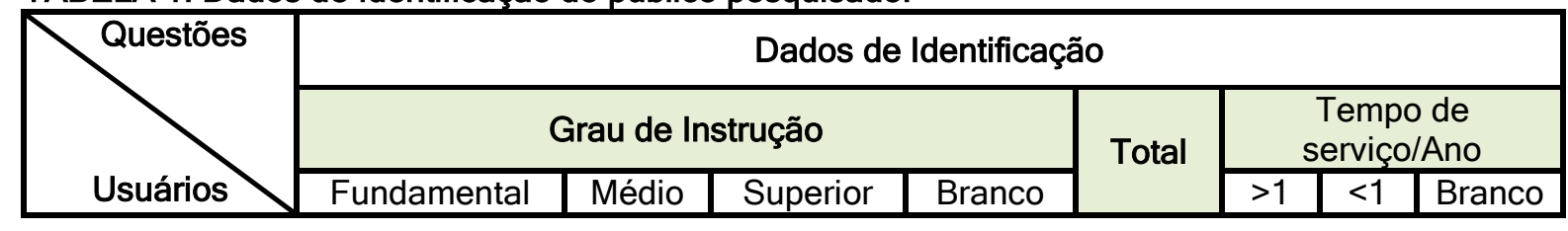

\footnotetext{
7 Essas equipes são constituídas de Médicos, Enfermeiros e Técnicos de Enfermagem, porém nesta pesquisa serão considerados apenas os Médicos e Enfermeiros.
} 


\begin{tabular}{|c|c|c|c|c|c|c|c|c|}
\hline Médico (a) & - & - & 4 & - & 4 & 4 & - & - \\
\hline Enfermeiro (a) & - & - & 8 & - & 8 & 4 & 3 & 1 \\
\hline ACS & - & 13 & 4 & 2 & 19 & 19 & - & - \\
\hline Total & - & 13 & 16 & 2 & 31 & 27 & 3 & 1 \\
\hline
\end{tabular}

Fonte: Elaborado pela autora.

Como se pode observar, através dos dados expostos na tabela, a maioria dos usuários que respondeu ao questionário possui nível superior, depois ensino médio e não existe nenhum usuário que pertença ao nível fundamental. Quanto ao tempo de serviço, a grande maioria tem acima de um ano de trabalho na Instituição. Nesse sentido, levando em consideração o tempo de serviço em que trabalham com instrumentos de coleta de dados para o SIAB, é de se supor que todos conheçam e saibam acessar e utilizar o SIAB, visto que esse sistema existe no município desde sua implantação no ano de 1998, conforme mencionado anteriormente.

Já no gráfico 2 estão expostos os dados que respondem ao segundo questionamento da pesquisa (Q2), assim como responde também a terceira questão (Q3).

GRÁFICO 2: Questões no2 e no3, sobre a necessidade de existência de um SIS e sobre o conhecimento da existência do SIAB, respectivamente.

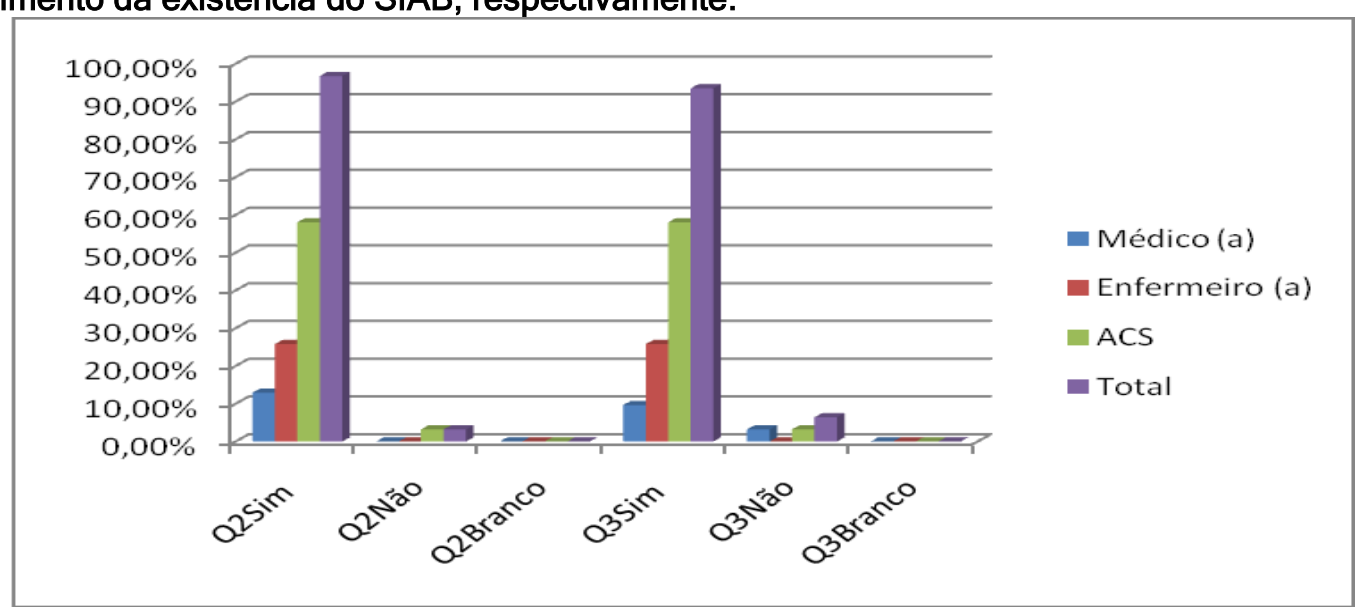

Fonte: Elaborado pela autora.

Como é possível perceber através do gráfico acima, dentre os 31 usuários pesquisados, tanto os médicos (as), quanto enfermeiros (as) e ACS responderam, em sua maioria (96,77\% dos usuários consultados), positivamente, que acreditam na existência da necessidade de um sistema de informação em saúde organizado e acessível que ofereça a possibilidade de consulta de informação pertinente ao desenvolvimento das ações de cada um. Dentre os outros 3,23\% usuários restantes 
estão os que disseram desconhecer ou simplesmente não quiseram opinar a respeito da questão.

Nesse sentido percebe-se o quão relevante é a existência de um sistema de informação em qualquer ambiente, pois de acordo com Robredo (2003, p. 110) "Sistema de informação é uma entidade complexa, organizada que capta, armazena, processa, fornece, usa e distribui informação." Com isso entende-se que os SIS são fontes de informação imprescindíveis para a atuação dos profissionais de saúde.

Em relação à questão no 3, 93,54\% disseram saber que o SIAB é um banco de dados que tem a finalidade de agregar, armazenar e processar todas as informações relacionadas ao PACS/PSF, enquanto que somente 6,46\% dos usuários disseram desconhecer a finalidade do SIAB no município. Vale ressaltar que "a informação em saúde é fundamental ao processo de tomada de decisões no âmago das políticas públicas, objetivando elevar a qualidade de vida dos povos." (TARGINO, 2006, p.217).

Desse modo, fica evidente que o SIAB é um sistema de considerável relevância para o município de Parnamirim, visto que detêm possibilidades para o gerenciamento da informação com foco em saúde.

No gráfico 3, é possível observar as respostas relacionadas à questão de número quatro (Q4) e à questão de número cinco (Q5).

GRÁFICO 3: Questão de no4: Conhecimento de quem atualiza dados no SIAB; e Questão no5: Conhecimento da utilidade do SIAB.

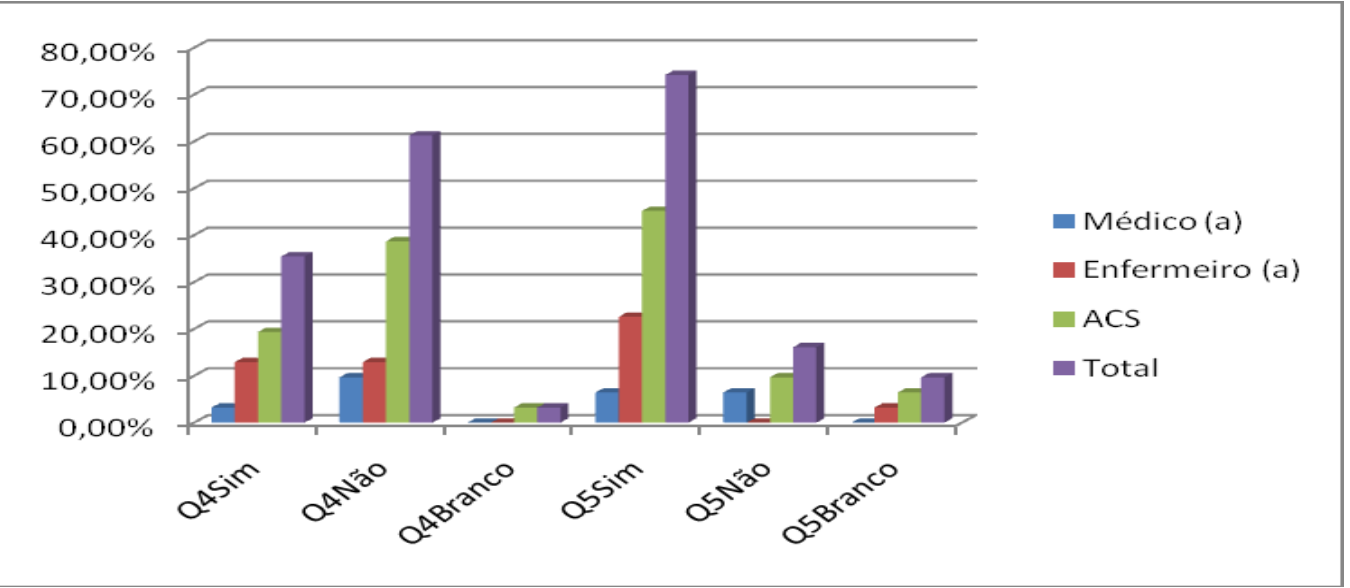

Fonte: Elaborado pela autora.

De acordo com o gráfico acima, 61,29\% dos usuários (3 médicos(as), 4 enfermeiros(as) e 12 ACS) responderam que não possuem conhecimento de quem é o profissional que atualiza os dados que são fornecidos pelas equipes de saúde ao 
SIAB, enquanto que $35,48 \%$ o equivalente a 11 usuários estão de comum acordo de que esses dados são atualizados por técnicos funcionários da SMS, sendo que entre os outros profissionais, $3,21 \%$ dos usuários pesquisados não responderam a questão.

Dessa forma é possível deduzir que apesar de pouco divulgado entre os principais colaboradores do SIAB ainda existe uma vaga noção entre os profissionais da saúde de quem é o possível responsável final pelas atualizações de informações dentro do sistema.

Em relação à questão de número $5,74,20 \%$ dos usuários pesquisados dizem saber qual a utilidade do SIAB para o município. Na opinião dos médicos (as) o SIAB serve para "fornecer dados para o planejamento das ações em saúde assim como melhorar a assistência a saúde do município". Para os enfermeiros (as) as opiniões são diversificadas e variadas e, dentre algumas, é possível citar aquela que diz que o SIAB serve para "nortear ações preventivas de saúde" e "armazenar informações". De acordo com os ACS, o SIAB fornece "informações para definir ações de estratégias no programa saúde da família" assim como "repasse financeiro do MS" dentre diversas opiniões.

Nesse sentido, Laudon e Laudon (1999, p.121) dizem que "a utilidade da informação depende muito de como elas são armazenadas, organizadas e acessadas. A resolução de problemas é difícil - por vezes impossível -, a menos que as informações necessárias estejam facilmente acessíveis na forma correta." A partir desta afirmação, é possível notar que os arranjos sociais nos quais se encontra a informação determinam o seu valor, já que uma mesma informação pode servir a diversos propósitos diferentes dentro de um mesmo sistema de informação.

Sendo assim, percebe-se que apesar da diversidade de opiniões sobre a utilidade do sistema, apenas $16,12 \%$ do público pesquisado desconhece a utilidade do SIAB. É positivo o fato da grande maioria dos usuários possuírem conhecimento da utilidade de um sistema tão relevante para o município, visto que o SIAB possibilita o desenvolvimento de ações estratégicas com base nas informações que estão agregadas e armazenadas no banco de dados.

A seguir será apresentado o gráfico 4 , o qual responde ao questionamento de número 6 da pesquisa de campo. 
GRÁFICO 4: Questão n6, sobre o conhecimento de quem tem acesso aos dados do SIAB.

Fonte: Elaborado pela autora.

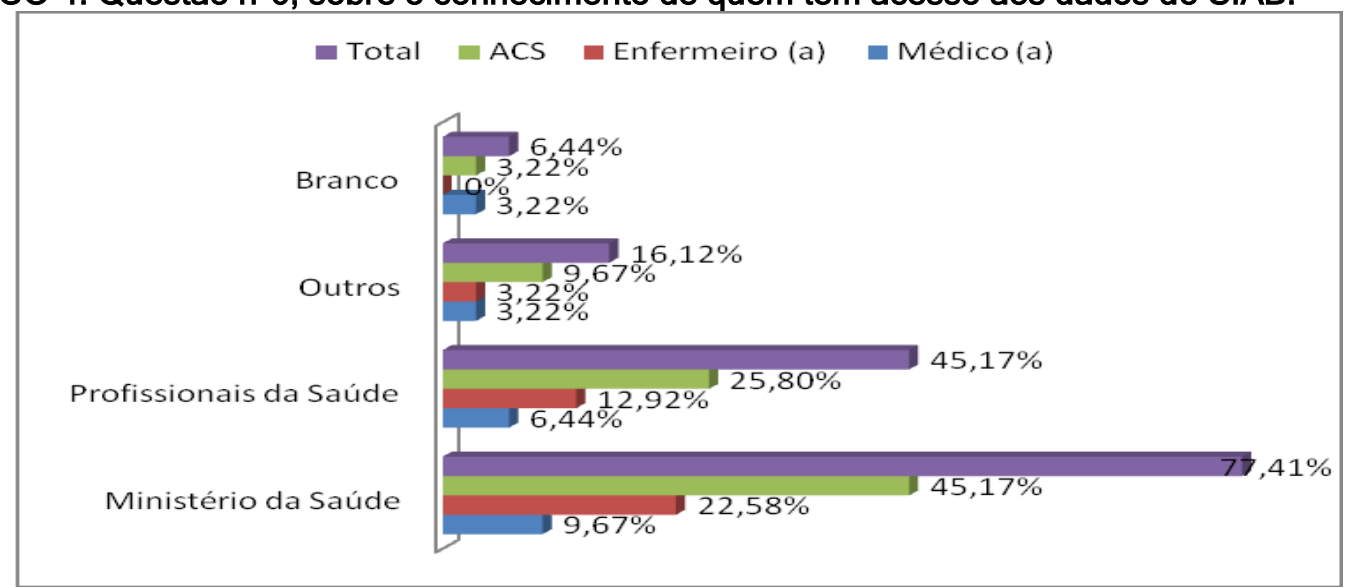

Desse modo como é possível perceber através do gráfico apresentado, este mostra que $77,41 \%$ do público pesquisado, o equivalente a 24 usuários, acreditam que apenas o MS e alguns profissionais da saúde possuem acesso aos dados inseridos no SIAB. Outros $16,12 \%$ acreditam que o acesso ao sistema somente é permitido aos digitadores e/ou coordenação do ESF. Nesse sentido, percebe-se que esse sistema não é acessado e utilizado diretamente pelas equipes locais de saúde com o objetivo de pesquisar informações e/ou desenvolver novas estratégias de atuação baseado nas informações disponíveis no sistema. Nota-se, porém, que existe um desconhecimento velado de quem ou como poderiam ser acessadas tais informações enviadas ao SIAB.

Em relação à questão de número 7 , que diz respeito a qual seria o principal empecilho no uso do SIAB, obtiveram-se respostas com opiniões diversificadas de $83,88 \%$ do público pesquisado. Dentre as respostas apresentadas estão às opiniões de que o principal empecilho encontrado é:

- a pouca divulgação das formas de acesso ao sistema;

- a inexistência de informatização globalizada que possibilite o acesso direto ao sistema pelas UBS;

- a falta de informação de como usar o sistema, aliado ao fato de não haver acesso às tecnologias de informação e comunicação através das UBS ou outro meio;

Assim, compreende-se que apesar da qualidade e potencial do sistema, este não oferece acesso em rede de domínio web para que os principais interessados nas informações que ali são armazenadas possam acessá-lo, mesmo que de forma limitada, através das ferramentas para a conectividade. 
A seguir são analisados os dados do gráfico 5 correspondentes às questões de número oito (Q8) e questão de número nove (Q9).

GRÁFICO 5: Questão de n8, sobre se o PACS/PSF acessa de forma direta as informações do SIAB e Questão de n9, sobre se as equipes desenvolvem estratégias com base no SIAB.

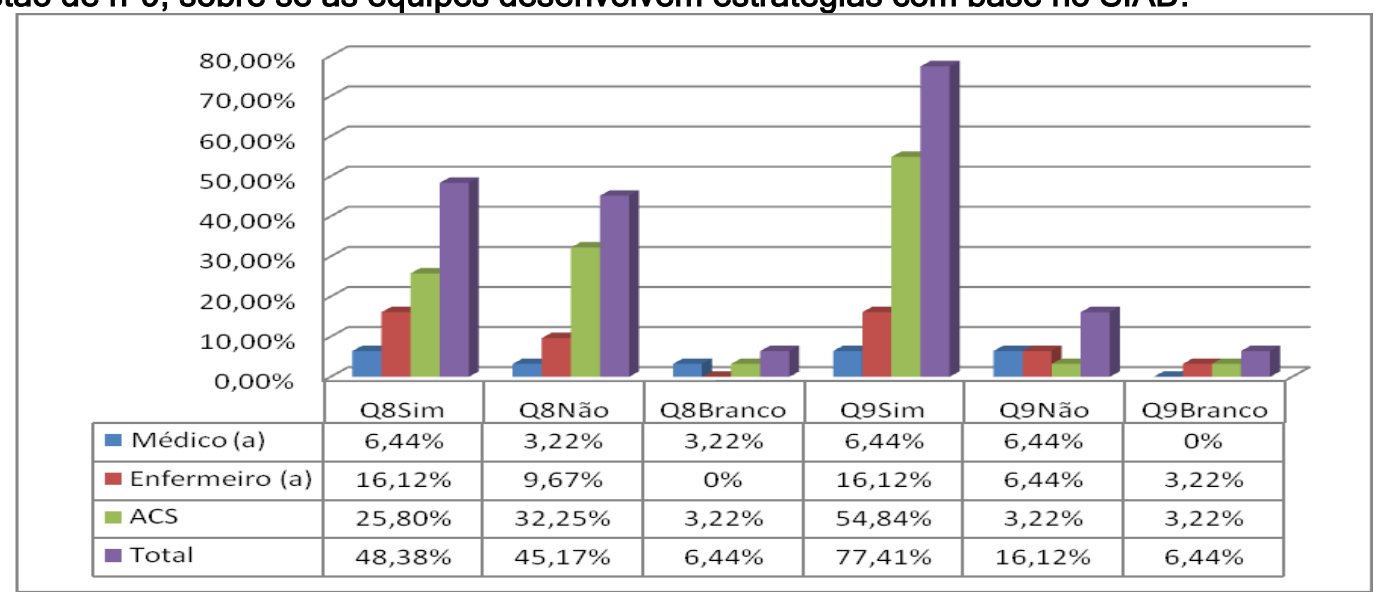

Fonte: Elaborado pela autora.

De acordo com os dados exibidos no gráfico acima, percebe-se que houve praticamente um empate entre respostas sim e não da questão de número 8 , pois do total de usuários questionados, 48,38\%, o equivalente a 15 pessoas, disseram possuir acesso às informações disponibilizadas no SIAB, enquanto que 45,17\%, 14 pessoas disseram não possuir nenhum acesso. Vale ressaltar, entretanto, que o acesso positivo referido diz respeito somente às informações em poder das equipes antes de serem enviadas a SMS, visto que de acordo com alguns dos profissionais "não existe retorno das informações enviadas".

Pode-se perceber, neste caso, que os profissionais sentem falta do feedback de informações enviadas ao sistema. Apesar de deixarem suas ações constantemente dependentes das decisões superiores, por não haver dados informacionais suficientes para desenvolver ações locais por equipes. Ainda assim, desenvolvem estratégias de atuação próprias, confiando apenas na memória individual e coletiva das equipes PACS/PSF em sua área local de saúde.

Em relação à questão 9 da pesquisa que segue, 77,41\%, cerca de 24 dos possíveis usuários do SIAB disseram desenvolver estratégias de atuação com base nas informações disponibilizadas no sistema. Há, porém, a ressalva de que essas estratégias não são diretamente desenvolvidas pelas equipes locais, mesmo assim, executam as ações de saúde solicitadas pelas autoridades da SMS, já que, como mencionado anteriormente, o SIAB não oferece acesso direto e de forma organizada às informações armazenadas no banco de dados. 
No gráfico 6 são mostradas as opiniões e respostas referentes aos questionamentos de número 10 (Q10) e de número 11 (Q11) da pesquisa realizada.

GRÁFICO 6: Questão de n¹0, sobre o conhecimento de quem organiza e gerencia o SIAB e Questão de no11, sobre acreditar na capacidade do profissional Bibliotecário auxiliando no SIAB.

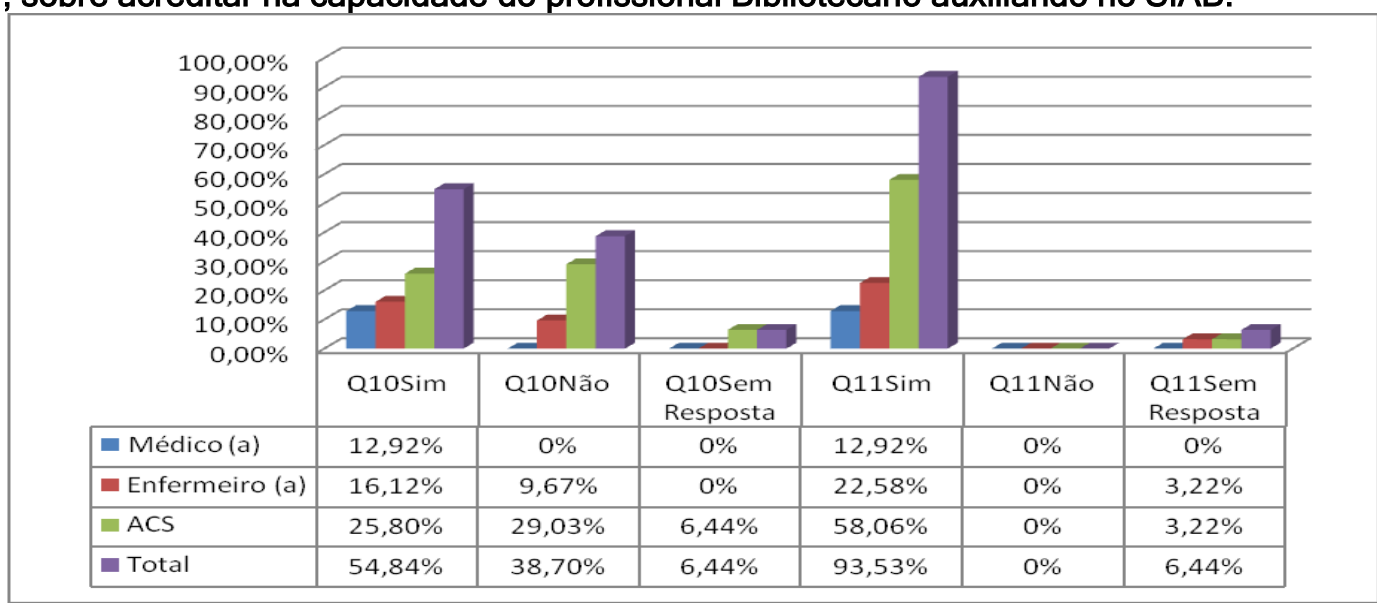

Fonte: Elaborado pela autora.

Respondendo ao 10 questionamento da pesquisa, considerando o gráfico acima, 17 pessoas, o equivalente a 54,84\% das pessoas pesquisadas acreditam saber da existência de um profissional capacitado para organizar e gerenciar as informações do SIAB na SMS, mostrando diversas suposições diferentes em relação ao tema. Dentre elas, a de que "deve ser algum profissional bem treinado e capacitado para o cargo". Enquanto que 38,70\% ou seja, 12 pessoas desconhecem quem é esse profissional responsável por organizar e disseminar essas informações, os outros $6,44 \%$ do público pesquisado preferiu não opinar a respeito. Assim, se pode perceber que há a inexistência de um saber real a respeito de quem organiza e como as informações tornam-se acessíveis nesse sistema de informação.

Sob essa perspectiva entende-se que "a informação deve ser ordenada, estruturada ou contida de alguma forma, senão permanecerá amorfa e inutilizável." (MCGARRY, p.11). Levando em conta essa ideia, parece correto afirmar que um entendimento mais completo em relação à busca de informação como sendo um comportamento social, pode colaborar, por sua vez, no desenvolvimento de melhores processos e sistemas de informação.

Ao analisar os resultados referentes à questão de número 11, percebe-se que $93,53 \%$ dizem que acreditam na necessidade de haver um profissional Bibliotecário para auxiliar na melhoria do gerenciamento do SIAB. Assim, segundo Smit e Barreto (2002), considerando que o domínio da base conceitual da ciência da 
informação é indispensável ao profissional Bibliotecário, entende-se que a competência conceitual favorece a compreensão desse profissional em relação a situações em constante mudança, tanto no que se refere às fontes de informação, suportes e tecnologias de tratamento e transmissão da informação, como também às formas de geração e às necessidades de informação da sociedade.

\section{CONSIDERAÇÕES FINAIS}

Em termos gerais a implantação de um sistema de informação tem por objetivo maior flexibilidade da organização para que esta tenha a possibilidade de acompanhar as mudanças ocorridas no ambiente externo. Assim, entende-se que a busca por informação, invariavelmente, ocorre com base em fatores que determinam a existência da necessidade de informação. A partir disso, acontece o uso direcionado da informação dentro do sistema.

Desse modo, com o objetivo esclarecer como acontece o uso do SIAB frente à demanda de informações fornecidas pelas equipes locais de saúde, PACS/PSF do município, percebeu-se que esse sistema apesar das informações que são enviadas ao seu banco de dados, não oferece acesso às informações propriamente, apenas possibilita consulta parcial de relatórios estatísticos, os quais se supõe que sejam enviados ao MS para repasse financeiro.

Outro fator é que, após o envio das informações pelas equipes de saúde, através dos instrumentos de coleta de dados, estas são atualizadas no sistema por digitadores contratados pela SMS, sem haver preocupação em disponibilizar as informações de forma acessível e organizada, tanto para o uso adequado e necessário dos gestores, quanto para o acesso dos principais colaboradores. Estes últimos ficam impossibilitados de visualizar as informações no SIAB, visto ser um sistema que possui características próprias e com função limitada, do qual ainda não foram desenvolvidas facilidades de acesso ao seu conteúdo informacional.

É preciso ainda salientar que talvez uma parte dos avanços ocorridos nos sistemas de informação em saúde possa ser atribuída ao processo de implantação do SUS, que coloca a descentralização dos sistemas de informação como um dos mecanismos para o seu gerenciamento. Neste sentido, a demanda por informações possibilita subsídios para a tomada de decisões nos níveis estadual, regional e 
municipal, funcionando como um elemento de influência que define estratégias de adequação e disseminação das informações em saúde.

Além disso, o desenvolvimento tecnológico ocorrido na área da informática configurou-se em um fato determinante para o aprimoramento dos mecanismos de disseminação das informações disponíveis. Ressalta-se, ainda, que as informações só podem colaborar para o avanço dos padrões sistemáticos de atenção à saúde se forem amplamente difundidas entre todos os profissionais da área que trabalham diretamente com esse sistema, mesmo que o acesso seja limitado a determinadas informações.

Em linhas gerais, pode-se destacar que os atuais sistemas de informações devem buscar atender a todas as necessidades de uma organização, possibilitando aos gestores a tomada de decisão apoiados em relatórios bem elaborados e com base em informações precisas. É de fundamental importância que os funcionários estejam integrados ao ambiente e às políticas de trabalho da empresa, pois os sistemas de informações oferecem a possibilidade de mudança nos objetivos iniciais de uma organização, em seus produtos e serviços, assim como também, nas relações internas e externas, alterando intensamente o caminho pelo qual a empresa administra seus negócios.

Em síntese, pretendeu-se demonstrar, por meio dessa pesquisa, que é estrategicamente relevante para os municípios buscar oferecer e manter um SIS organizado e acessível aos seus principais colaboradores, que neste caso, tratam-se das equipes locais de saúde, PACS/PSF, de modo a possibilitar acesso adequado à informação tratada e organizada para recuperação rápida e uso eficaz. É preciso também levar em consideração que o que move estes sistemas é o feedback e este pode ser gerado a partir do acesso contínuo das informações disponibilizadas.

As equipes de saúde necessitam ter acesso aos conhecimentos armazenados no SIAB, dos quais são responsáveis por atualizar, através de técnicas e procedimentos apropriados. Também podem sanar necessidades imprescindíveis às suas ações com a obtenção de informação rápida e segura, servindo de subsídio essencial ao desenvolvimento adequado de estratégias de atuação no ambiente.

Torna-se evidente, ainda, que a atuação do Bibliotecário é fator primordial em qualquer ambiente que necessite de informação organizada, acessível, rápida e eficaz. Ao perceber uma necessidade urgente de informação para guiar suas ações, o bibliotecário busca, através de técnicas e procedimentos próprios, desenvolver 
juntamente com outros profissionais capacitados, o melhor desempenho do sistema de informação para atender às necessidades informacionais dos seus usuários.

\section{REFERÊNCIAS}

AUDY, Jorge Luis Nicolas; ANDRADE, Gilberto Keller de; CIDRAL, Alexandre. Fundamentos de sistemas de informação. Porto Alegre: Bookman, 2005.

BATISTA, Emerson de Oliveira. Sistemas de informação: o uso consciente da tecnologia para o gerenciamento. São Paulo: Saraiva, 2004.

BEUREN, Ilsen Maria. Gerenciamento da informação: um recurso estratégico no processo de gestão empresarial. São Paulo: Atlas, 1998.

BITTAR, Telmo Oliveira et al. O sistema de informação da atenção básica como ferramenta da gestão em saúde. RFO, Passo Fundo, RS, v. 14, n. 1, p. 77-81, jan./abr. 2009. Disponível em: <http://www.upf.br/download/editora/revistas/rfo/1401/77_81.pdf>. Acesso em: 30 set. 2013.

BRASIL. Ministério da saúde. A experiência brasileira em sistemas de informação em saúde: produção e disseminação de informações sobre saúde no Brasil. Brasília, DF: MS, 2009. Disponível em:

<http://bvsms.saude.gov.br/bvs/publicacoes/experiencia_brasileira_sistemas_saude _volume1.pdf>. Acesso em: 30 set. 2013.

BRASIL. Ministério da saúde. SIAB: manual do sistema de informação da atenção básica. 1. ed. Brasília, DF: MS, 2003. Disponível em:

<http://dtr2001.saude.gov.br/editora/produtos/livros/pdf/03_1543_M.pdf>. Acesso em: 30 set. 2013.

BRASIL. Ministério da saúde. Sistema de informação da atenção básica. 2008. Disponível em: <http://siab.datasus.gov.br/SIAB/index.php?area=01>. Acesso em: 30 set. 2013.

DAVENPORT, Thomas H. Ecologia da informação: por que só a tecnologia não basta para o sucesso na era da informação. Tradução Bernadette Siqueira Abrão. 5. ed. São Paulo: Futura, 2002.

GIL, Antonio Carlos. Como elaborar projeto de pesquisa. 5.ed. São Paulo: Atlas, 2010.

LAUDON, Kenneth C; LAUDON, Jane Price. Sistemas de informação: com Internet. Tradução Dalton Conde de Alencar. 4. ed. Rio de Janeiro: LTC, 1999.

LE COADIC, Yves-François. A ciência da informação. Tradução Maria Yêda F. S. Filgueiras Gomes. 2. ed. Brasília, DF: Brinquet de Lemos, 2004.

MACGARRY, Kevin. O contexto dinâmico da informação: uma análise introdutória. Tradução Helena Vilar de Lemos. Brasília, DF: Brinquet de Lemos, 1999. 
MARCONI, Marina de Andrade; LAKATOS, Eva Maria. Técnicas de pesquisa: planejamento e execução de pesquisas, amostragens e técnicas de pesquisa, elaboração, análise e interpretação de dados. 2. ed. rev. ampl. São Paulo: Atlas, 1990.

MATIAS-PEREIRA, José. Manual de metodologia da pesquisa científica. 2. ed. São Paulo: Atlas, 2010.

MEDEIROS, Francisca Gilca da Silva. Sistemas de informação em saúde: considerações fundamentais. In: TARGINO, Maria das Graças; CASTRO, Mônica M. M. R. N. de. (Org.). Desafiando os domínios da informação. Teresina: EDUFPI, 2002. p. $119-127$.

O'BRIEN, James A.. Sistemas de informação e as decisões gerenciais na era da Internet. 2. ed. São Paulo: Saraiva, 2004.

ORGANIZAÇÃO PAN-AMERICANA DA SAÚDE. Sistemas de informação geográfica em saúde: conceitos básicos. Brasília: OPAS, 2002.

ROBREDO, Jaime. Da ciência da informação revisitada aos sistemas humanos de informação. Brasília, DF: Thesaurus, 2003.

SANTOS, Jussara Pereira. O perfil do profissional bibliotecário. In: VALENTIM, Marta Pomim. (org.). O profissional da informação: formação, perfil e atuação profissional. São Paulo: Polis, 2000. p. 107-117.

SANTOS, Plácida L.V. Amorim da Costa. As novas tecnologias na formação do profissional da informação. In: VALENTIM, Marta Lígia. (org.). Formação do profissional da informação. São Paulo: Polis, 2002. p. 103-116.

SILVA, Anderson Soares da; LAPREGA, Milton Roberto. Avaliação Crítica do sistema de informação da atenção básica (SIAB) e de sua implantação na região de Ribeirão Preto, São Paulo, Brasil. Cad. Saúde pública. Rio de Janeiro, v. 21, n.6, p. 1821-1828, nov./dez. 2005. Disponível em:

<http://www.scielosp.org/pdf/csp/v21n6/21.pdf>. Acesso em: 01 out. 2013.

SILVA, Terezinha Elisabeth da; TOMAÉL, Maria Inês. A gestão da informação nas organizações. Inf. Inf., Londrina, v. 12, n. 2, jul./ dez. 2007. Disponível em: < http://www.uel.br/revistas/uel/index.php/informacao/article/view/1806/1540 >. Acesso em: 01 out. 2013.

SMIT, Johanna W.; BARRETO, Aldo de Albuquerque. Ciência da informação: base conceitual para a formação do profissional. In: VALENTIM, Marta Lígia. (org.).

Formação do profissional da informação. São Paulo: Polis, 2002. p. 09-23.

TARAPANOFF, Kira. Referencial teórico: introdução. In: TARAPANOFF, Kira (org.). Inteligência organizacional e competitiva. Brasília: UNB, 2001. p. 33-49.

TARGINO, Maria das Graças. Olhares e fragmentos: cotidiano da biblioteconomia e ciência da informação. Teresina, PI: EDUFPI, 2006. 
VALENTIM, Marta Lígia Pomim. Atuação e perspectivas profissionais para o profissional da informação. In: VALENTIM, Marta Pomim. (org.). O profissional da informação: formação, perfil e atuação profissional. São Paulo: Polis, 2000. p. 135152.

VALENTIM, Marta Lígia Pomim. Formação: competências e habilidades do profissional da informação. In: VALENTIM, Marta Lígia. (org.). Formação do profissional da informação. São Paulo: Polis, 2002. p. 117-132. 